\title{
Materno-Fetal Outcomes of COVID-19 Infected Pregnant Women Managed at the Douala Gyneco-Obstetric and Pediatric Hospital-Cameroon
}

\author{
Alphonse Nyong Ngalame ${ }^{1 *}$, Humphry Tatah Neng ${ }^{1}$, Rakya Inna ${ }^{1,2}$, Dominique Tamchom Djomo', \\ Diane Estelle Modjo Kamdem¹, Bilkissou Moustapha1, Julie Ngo Batta1, \\ Diomede Njinkui Noukeu1,3, Dominique Enyama1,3, Rodrigue Tiokeng1, Yannick Onana1,2, \\ Yves Moumbe1, Martial Zanga', Jules Fils Ndongo', Armand Kamga', Robert Tchounzou', \\ Ultrich Keumayou $^{1}$, Lemone Chingnabo ${ }^{1}$, Toudjirob Djiallati ${ }^{1}$, Emmanuel Passoret ${ }^{1}$, \\ Estella Toyoum Ramadji ${ }^{1}$, Jean Blaise Ebimbe' ${ }^{1}$, Servais Albert F. Bagnaka Eloumou ${ }^{1,6}$, \\ Darolles Wekam Mwadjie1, Guy Pascal Ngaba1,6, Emile Telesphore Mboudou,4,6 \\ ${ }^{1}$ Gynecology and Obstetrics Unit, Douala Gyneco-Obstetric and Pediatric Hospital, Douala, Cameroon \\ ${ }^{2}$ Faculty of Medicine and Biomedical Sciences, University of Ngaoundere, Ngaoundere, Cameroon \\ ${ }^{3}$ Faculty of Medicine and Pharmaceutical Sciences, University of Dschang, Dschang, Cameroon \\ ${ }^{4}$ Faculty of Medicine and Biomedical Sciences, University of Yaounde I, Yaounde, Cameroon \\ ${ }^{5}$ Faculty of Health Sciences, University of Buea, Buea, Cameroon \\ ${ }^{6}$ Faculty of Medicine and Pharmaceutical Sciences, University of Douala, Douala, Cameroon \\ Email: *anngalame2000@gmail.com
}

How to cite this paper: Ngalame, A.N., Neng, H.T., Inna, R., Djomo, D.T., Kamdem, D.E.M., Moustapha, B., Batta, J.N., Noukeu, D.N., Enyama, D., Tiokeng, R., Onana, Y., Moumbe, Y., Zanga, M., Ndongo, J.F., Kamga, A., Tchounzou, R., Keumayou, U., Chingnabo, L., Djiallati, T., Passoret, E., Ramadji, E.T., Ebimbe, J.B., Eloumou, S.A.F.B., Mwadjie, D.W., Ngaba, G.P. and Mboudou, E.T. (2020) Materno-Fetal Outcomes of COVID-19 Infected Pregnant Women Managed at the Douala Gyneco-Obstetric and Pediatric Hospital-Cameroon. Open Journal of Obstetrics and Gynecology, 10, 1279-1294.

https://doi.org/10.4236/ojog.2020.1090118

Received: August 15, 2020

Accepted: September 20, 2020

Published: September 23, 2020

\section{Abstract}

Introduction: The first case of the novel coronavirus (COVID-19) pandemic in Cameroon was confirmed on March 6, 2020. Though widely considered that pregnant women are more susceptible to respiratory tract infections, the available body of literature on the effect of COVID-19 on pregnancy outcomes is shy from being conclusive. In Cameroon, the Douala Gyneco-Obstetric and Pediatric Hospital (DGOPH) was one of the main frontline tertiary health facilities for the management of severe forms of the disease. After four months of managing COVID-19 cases in the general population and especially in pregnant women at the DGOPH, we decided to take a stop, analyze our findings from the patients managed in order to drive future policies and clinical practices via informed decisions. Overall objective: To describe and understand the clinical burden of patients managed for COVID-19 in pregnancy or post-partum at the DGOPH. Methodology: Cross-sectional and descriptive study covering four months-March $24^{\text {th }}$ to July $24^{\text {th }} 2020$ at DGOPH. Using a pretested questionnaire, we systematically enrolled all pa- 
Copyright $\odot 2020$ by author(s) and Scientific Research Publishing Inc. This work is licensed under the Creative Commons Attribution International License (CC BY 4.0).

http://creativecommons.org/licenses/by/4.0/ tients who fulfilled the inclusion criteria, with analysis done using proportions from an excel spreadsheet. Results: A total of 18 on the 301 pregnant women consulted at the DGOPH, tested positive for COVID-19 giving a prevalence of $6 \%$, and representing $2.3 \%$ of all the 800 COVID- 19 cases. Of the 44 pregnant women admitted at the DGOPH, 13 of them were due to COVID-19, giving a general admission proportion of $29.5 \%$ and a COVID-19 case admission rate of $72.2 \%$. Two-thirds $(66.7 \%)$ of the patients were aged 30 - 39 years and over $61.1 \%(n=11)$ of the total cases were referred from other health facilities for better management. The most common presenting symptoms were: fever (27.4\%), cough (21.5\%) and dyspnea (15.7\%). Over $72.2 \%$ of cases were in their third trimester, and only three had comorbidities. Nasal throat swab PCR was mainstay for confirmatory diagnosis (83.3\%). Chest CT scan was realized in $50 \%(n=9)$ of the patients and ground glass opacification (GGO) was observed in all of them. All 18 patients received the standard national recommended regimen therapy for COVID-19. While five of the cases are ongoing gestations, 8 of them were delivered by cesarean section (61.5\%), mostly indicated for maternal distress. The neonatal mortality rate was $46 \%$. Four of the 18 patients died giving a case fatality rate of $22.2 \%$. Conclusion: The profile of COVID-19 pregnant women in Douala-Cameroon tends to be similar to what is observed around the world. However, the high ICU admission rate and high case fatality rates recorded differ from what is observed worldwide.

\section{Keywords}

COVID-19, DGOPH, Pregnancy, Outcome, Mortality

\section{Introduction}

First described in the Chinese city of Wuhan in Nov 2019, the novel coronavirus (SARS COV-2) was confirmed as the cause of an acute respiratory illness by the World Health Organization (WHO) on the $12^{\text {th }}$ January 2020 [1]. This coronavirus disease of 2019 (COVID-19) was declared a pandemic by the WHO on March $11^{\text {th }} 2020$ [2].

The first case of COVID-19 in Cameroon was confirmed on March $6^{\text {th }} 2020$ in Yaounde [3]. The infected person was a French national who arrived at the country on $24^{\text {th }}$ February 2020. Meanwhile, the country recorded its first case of death due to COVID-19 on $24^{\text {th }}$ march 2020 [4]. Since then, several measures have been taken by government to curb the spread of the pandemic in the country. These include: the closing of national borders, the respect of social distancing and barrier measures such as obligatory wearing of face masks in public space and regular washing of hands [5]. However, these measures have hardly been fully followed by the population, leading to a spike in the number of new cases. As of today $24^{\text {th }}$ July 2020, Cameroon had tested a total of 145,000 persons, with 16,708 positive cases and a severity rate of $1.7 \%$. Of these contaminations, 
14,539 cases were cured, 385 deaths recorded and a specific mortality rate of $2.3 \%$ [6]. It is worth noting that a total of 49 pregnant women were contaminated during that period [6].

Though a recent infection, sufficient body of literature already exists in support of the efficacy of diagnostic techniques of COVID-19. Reverse Transcription Polymerase Chain Reaction (RT-PCR) is the gold standard test via a naso-pharyngeal swab elucidating viral particles. Its sensitivity though can be as low as $70 \%$, due to its dependence on sample collection technique. Chest computerized tomography (CT) scan tends to have a higher sensitivity of over $90 \%$ in later phase of the disease by putting to evidence the pathognomonic radiologic sign of ground glass opacification (GGO). The serum of COVID-19 positive patients tends to reveal abnormally raised values of certain biological pro-inflammatory markers such as the lactate dehydrogenase ( $\mathrm{LDH}$ ) enzyme, $\mathrm{C}$ reactive protein (CRP), procalcitonin (PCT) and even creatine phosphokinase (CPK). These markers alongside D-dimers are regularly used as predictors of maternal outcome, since their increments are associated with multiple organ failure, pulmonary embolism and death.

It is widely considered that pregnant women are more susceptible to respiratory tract infections such as those due to coronavirus than the general population [7]. This holds more if they suffer from other comorbidities such as asthma, diabetes, hypertension, renal diseases and obesity [8]. It is reported that the clinical manifestations of COVID-19 in pregnant women are similar to those of the general population [7]. There are however inconclusive data reporting the effect of COVID-19 on pregnancy outcomes. Some studies found an increase in certain materno-fetal complications such as; preterm delivery, premature rupture of membranes, acute fetal distress and risk of cesarean delivery [9]. How the course of the novel coronavirus infection is affected by gestation is still to be proven. Similarly, vertical transmission of COVID-19 either through the placenta or breast milk has not yet been elucidated [10]. However, desiring breastfeeding mothers need to wear face masks during contact with the newborn.

In order to better manage moderate to severe symptomatic cases of COVID-19, the government designated certain health facilities in all the ten regions of the country. In the economic capital of Douala, three hospitals have been equipped to cater for these severe cases. They include; the Douala General Hospital (DGH), the Douala Laquintini Hospital (DLH) and the Douala Gyneco-Obstetric and Pediatric Hospital (DGOPH).

The DGOPH is a tertiary university teaching hospital in the city of Douala, assigned to offer state of the art care in mother and child health in Cameroon in particular and the central African sub-region in general. It can boast of having many specialists such as; molecular and clinical biologists, radiologists, gynecologists and obstetricians, as well as anesthetists and intensive care physicians. It is in this light that pregnant women and those in the post-partum suspected or confirmed for COVID-19 infection from all over the region and beyond are 
mostly referred here for better management.

After a more than four months period of experience managing COVID-19 cases in the general population and with keen focus in pregnant women at the DGOPH, we decided to analyze findings from the patients we have been receiving this far and inform the scientific community. Our rationale was based not only on the novel nature of this disease, but equally on the progressively increasing number of contaminated pregnant women with adverse maternofetal outcomes. A proper understanding of the effects of this pandemic affecting pregnant women in our hospital is mandatory in order to shape future studies of associations, outcome predictors as well as reorient our therapeutic strategy for the better. It is mindful of these two routine observations that we decided to carry out this study on the clinical, biological, radiological and outcome characteristics of pregnant women and those in post-partum diagnosed for COVID-19 and managed at the DGOPH.

\section{Overall Objective}

To describe and better understand the clinical burden of patients diagnosed with COVID-19 in pregnancy or postpartum and managed at the DGOPH.

\section{Methodology}

\subsection{Study Design}

Cross sectional and descriptive study.

\subsection{Study Period}

Four months period from March $24^{\text {th }}$ to July $24^{\text {th }} 2020$ at the Douala Gyneco-Obstetric and Pediatric Hospital.

\subsection{COVID-19 Management Protocol at the DGOPH}

For every pregnant woman suspected or confirmed with COVID-19 at the $\mathrm{DGOPH}$, there is a clear pre-defined diagnostic and management protocol put in place by the scientific multidisciplinary committee of the hospital and in line with national guidelines.

A suspected case is any patient presenting with some of the following symptoms; fever, flu, cough, loss of taste, loss of sense of odour, fatigue, headaches and respiratory distress, and for whom the COVID-19 test results are being awaited. This suspicion is strengthened by the patient's recent history of either travelling from a country or region with high viral spread or has come into contact with a confirmed case of COVID-19 in the past 14 days. Meanwhile, a confirmed case is any patient with a positive para clinical test; PCR-RT throat swab, or rapid diagnostic test (RDT) for COVID-19, or ground glass opacification (GGO) on chest CT scan.

All cases were then separated into 2 groups: 1) mild cases presenting with mild symptoms but not necessitating admission neither in the common ward 
nor in the intensive care unit (ICU), and 2) moderate to severe cases who presented more severe symptoms and were either admitted in the common ward (moderate cases) and the ICU (severe respiratory distressed cases) for electronic monitoring and oxygenation.

Be it in outpatient or admitted in ICU, all contaminated pregnant women received the same treatment protocol for COVID-19, which was composed of; 1) Chloroquine tablets $100 \mathrm{mg}$ : $200 \mathrm{mg}$ every 8 hours for 7 days, 2) Azithromycin $250 \mathrm{mg}$ tablets: $250 \mathrm{mg}$ every 12 hours on day 1 followed by $250 \mathrm{mg}$ daily for 4 days, 3) Zinc $20 \mathrm{mg}$ tablets: 1 tablet daily for 10 days, 4) Vitamin D tablets, 5) Corticosteroid Prednisolone $5 \mathrm{mg}$ tablets daily, 6) Anticoagulation was ensured using mostly low molecular weight heparin (enoxaparin) 8000 IU daily and rarely via Rivaroxaban in the absence of any contraindication. Exclusively for cases admitted into the ICU, oxygen-therapy was added without intubation. The care was offered by health personnel wearing high quality personal protective equipment (PPE) including; face masks, caps, transparent plastic face shields, gown, clogs, glasses and sterile gloves.

\subsection{Study Population}

All patients consulted at the DGOPH during the study period and who met with the inclusion criteria.

\subsection{Inclusion and Exclusion Criteria}

Were included in the study, all confirmed and/or suspected cases of COVID-19 in pregnancy or postpartum and managed at the DGOPH during the study period and for whom complete files were available. Conversely, were excluded all those who did not meet these inclusion criteria.

\subsection{Sampling Method}

Systematic and continuous enrollment of all those who fulfill the inclusion criteria. This was done via a pretested anonymous questionnaire designed by a multidisciplinary team of obstetricians, the intensive care physician and with technical assistance from the data manager. We had a total of 77 items on the question guide in the appendix.

\subsection{Study Variables and Data Analysis}

The following outcome variables were investigated: 1) Socio-demographic characteristics; age, residence, level of education, marital status, recent travels and recent COVID contacts. 2) Clinical and obstetrical characteristics; parity, age and trimester of pregnancy, presenting symptoms, past medical and surgical histories, blood group, oxygen saturation and COVID-19 status. 3) Biological parameters; COVID-19 PCR test, RDT result, liver and kidney function tests, clotting profile, D-Dimers, LDH, CPK, PCT, CRP, hemogram. 4) Radiologic parameters; Chest CT scan results and severity. 5) Materno-fetal outcome charac- 
teristics; Mode of delivery, treatment regimen received, barrier measures respected, maternal outcome, APGAR score, birth weight, transfer to NICU, COVID test results for newborns and newborn survival outcomes. Results will be analyzed by using the excel computer software and presented as proportions in tables.

\subsection{Ethical Considerations}

Authorization to carry out this research was obtained from the managing director of the DGOPH. Ethical clearance was equally sought and gotten from the Institutional Ethics Committee (IEC) of the DGOPH. This permitted us to use both the electronic and physical files of patients consulted and managed in the hospital during the study period. Anonymity will be respected by coding the files and guaranteed that patient's names or identification will not be disclosed on any study document.

\section{Results}

Throughout the study period, and with over 800 detected cases of COVID-19 in the general population, the DGOPH was the health facility that diagnosed the greatest number of infected persons in the country. During these four months, a total of 301 pregnant women were consulted at the DGOPH, with 18 of them testing positive for COVID-19 giving a prevalence of the disease in pregnant women of $6 \%$, and a proportion of pregnant COVID-19 cases on the total hospital COVID-19 burden of 2.3\%. Similarly, amongst all the 44 pregnant women admitted at the DGOPH during the study period, 13 of them were due to COVID-19, giving a general admission proportion of $29.5 \%$ and a case admission rate of $72.2 \%$.

Two-thirds (66.7\%) of the patients were aged 30 - 39 years, while only one of them was older. More than half (55.6\%) of the women had delivered once or twice before with none being a grand multiparous. Two-thirds (61.1\%) of cases had secondary education, $83.3 \%$ were married and over $61.1 \%(n=11)$ of the total cases were referred from other health facilities for better management (Table 1).

The most common symptoms presented by the COVID-19 positive pregnant women were; fever (27.4\%), cough (21.5\%), dyspnea (15.7\%), fatigue (11.8\%) and joint pains $(9.8 \%)$. There were no cases with anosmia and dysphagia. In $72.2 \%(n=13)$ of the cases, the women were in their third trimester of gestation, with two of them in the first trimester (10 weeks twin gestation and 8weeks singleton) at diagnosis. Only three (16.7\%) of the 18 women had chronic diseases. The comorbidities were; type 2 diabetes, renal disease and asthma. Most of the cases $(61.1 \%)$ had an oxygen saturation of $85 \%$ - $98 \%$ free air, with none desaturating under $70 \%$. Over $72.2 \%(n=13)$ of the cases were confirmed before management was started, while the remainder were managed as suspected cases of the disease. Though they were later confirmed during admission (Table 2). 
Table 1. Socio-demographic characteristics of COVID-19 pregnant patients at DGOPH.

\begin{tabular}{|c|c|c|}
\hline Variables & Total & Percentage \\
\hline Age group (years) & $\mathrm{n}=18$ & $\%$ \\
\hline [20 - 29] & 05 & 27.8 \\
\hline [30 - 39] & 12 & 66.7 \\
\hline$\geq 40$ & 01 & 05.5 \\
\hline Parity & $\mathrm{n}=18$ & $\%$ \\
\hline 0 & 04 & 22.2 \\
\hline$[1-2]$ & 10 & 55.6 \\
\hline$[3-4]$ & 04 & 22.2 \\
\hline$\geq 5$ & 00 & 00 \\
\hline Level of education & $\mathrm{n}=18$ & $\%$ \\
\hline Primary & 00 & 00 \\
\hline Secondary & 11 & 61.1 \\
\hline University & 07 & 38.9 \\
\hline Marital status & $\mathrm{n}=18$ & $\%$ \\
\hline Married & 15 & 83.3 \\
\hline Single & 02 & 11.1 \\
\hline Divorced & 01 & 05.6 \\
\hline Widow & 00 & 00 \\
\hline Origin of cases & $\mathrm{n}=18$ & $\%$ \\
\hline DGOPH & 07 & 38.9 \\
\hline Referred & 11 & 61.1 \\
\hline
\end{tabular}

DGOPH: Douala Gyneco-Obstetric and Pediatric Hospital.

Table 2. Clinical characteristics of the pregnant patients with COVID-19 at DGOPH.

\begin{tabular}{ccc}
\hline Variables & Total & Percentage \\
\hline Symptoms & $\mathrm{n}=51$ & $\%$ \\
Catarrh & 01 & 2 \\
Cough & 11 & 21.5 \\
Fever & 14 & 27.4 \\
Headaches & 03 & 05.9 \\
Fatigue & 06 & 11.8 \\
Joint pains & 05 & 09.8 \\
Dyspnea & 08 & 15.7 \\
Dysphagia & 00 & 00 \\
Anosmia/Aguesia & 00 & 00 \\
Others & 01 & 2 \\
Asymptomatic & 02 & 3.9 \\
Pregnancy age at diagnosis & $\mathrm{n}=18$ & $\%$ \\
$1^{\text {st }}$ Trimester & 02 & 11.1 \\
$2^{\text {nd }}$ Trimester & 03 & 16.7
\end{tabular}




\section{Continued}

\begin{tabular}{ccc}
\hline $3^{\text {rd }}$ Trimester & 13 & 72.2 \\
Labour & 00 & 00 \\
Post-partum & 00 & 00 \\
Chronic disease & $\mathrm{n}=18$ & $\%$ \\
Type II diabetes & 01 & 05.6 \\
Kidney disease & 01 & 05.6 \\
Asthma & 01 & 05.6 \\
Unavailable & 15 & 83.3 \\
SaO \\
(\%) & $\mathrm{n}=18$ & $\%$ \\
[70 - 84] & 00 & 00 \\
{$[85$ - 98] } & 01 & 05.6 \\
$>98$ & 11 & 61.1 \\
Diagnosis & 06 & 33.3 \\
Suspected cases & $\mathrm{n}=18$ & $\%$ \\
Confirmed cases & 05 & 27.8 \\
& 13 & 72.2
\end{tabular}

$\mathrm{SaO}_{2}$ (\%): Partial oxygen saturation. DGOPH: Douala Gyneco-Obstetric and Pediatric Hospital.

Of the 18 cases, the confirmatory test used was PCR (83.3\%) and RDT (16.7\%). The prognostic biological markers most assayed were; CRP (38.9\%), PCT (38.9\%) and D-Dimers (16.7\%). None of the patients did the CPK with only one sample of $\mathrm{LDH}$ analyzed. Among the women, $44.4 \%$ were of blood group $\mathrm{O}$ and $44.4 \%$ of group B (Table 3 ).

The chest CT scan was realized in 50\% $(\mathrm{n}=9)$ of the patients. The radiologic results revealed ground glass opacification (GGO) in $100 \%$ of the cases. The severity of the GGO reflected via the proportion of affected lung tissue was moderate 50\% (44.5\%), mild 25\% (33.3\%) and severe 75\% (22.2\%) (Table 3).

The standard protocol of management was instituted in all the 18 patients. With five of the women still pregnant, 8 of the patients delivered by cesarean section (61.5\%), 5 by vaginal delivery and none was instrumental. The indications for cesarean section was maternal distress in $87.5 \%(n=7)$ and one case of cephalopelvic disproportion. Of these 13 women who delivered, 6 (46.2\%) were at term of at least 37 weeks and $4(30.8 \%)$ were at a gestational age (GA) younger than 34 weeks. Four of the women died during their hospital stay at the ICU giving a specific mortality rate of $22.2 \%$ (Table 4 ).

Almost equal numbers of the newborns were of male and female sexes, with $30 \%$ of them weighing less than $2500 \mathrm{~g}$, a single case of macrosomia ( $\geq 4000 \mathrm{~g}$ ) and most of them with normal birth weights. The APGAR scores were $<7$ (38.5\%) and $\geq 7(61.5 \%)$ at the first minute and $<7(23 \%)$ and $\geq 7(77 \%)$ at the fifth minute. Over $61.5 \%(n=8)$ of these neonates were admitted to the neonatal intensive care unit (NICU). Of the 10 neonates delivered at age of viability, 4 died before leaving the NICU, giving a specific neonatal mortality rate of $40 \%$. Only three of the neonates had a COVID 19 test done and 100\% were negative. 
Table 3. Biological and radiological parameters of pregnant COVID-19 cases at DGOPH.

\begin{tabular}{|c|c|c|}
\hline Variables & Total & Percentage \\
\hline Biological diagnosis & $\mathrm{n}=18$ & $\%$ \\
\hline PCR & 15 & 83.3 \\
\hline RDT-Ag & 03 & 16.7 \\
\hline Prognostic factors & $\mathrm{n}=18$ & $\%$ \\
\hline $\mathrm{LDH}$ & 01 & 05.5 \\
\hline $\mathrm{CPK}$ & 00 & 00 \\
\hline PCT & 07 & 38.9 \\
\hline D-Dimers & 03 & 16.7 \\
\hline CRP & 07 & 38.9 \\
\hline Blood group & $\mathrm{n}=18$ & $\%$ \\
\hline A & 00 & 00 \\
\hline B & 04 & 22.2 \\
\hline $\mathrm{AB}$ & 01 & 05.6 \\
\hline $\mathrm{O}$ & 04 & 22.2 \\
\hline Unavailable & 09 & 50 \\
\hline Chest CT scan & $\mathrm{n}=18$ & $\%$ \\
\hline Not done & 09 & 50 \\
\hline Done & 09 & 50 \\
\hline Scan results & $\mathrm{n}=09$ & $\%$ \\
\hline Normal & 00 & 00 \\
\hline GGO & 09 & 100 \\
\hline Other lesions & 00 & 00 \\
\hline Severity of GGO & $\mathrm{n}=09$ & $\%$ \\
\hline $25 \%$ & 03 & 33.3 \\
\hline $50 \%$ & 04 & 44.5 \\
\hline $75 \%$ & 02 & 22.2 \\
\hline
\end{tabular}

DGOPH: Douala Gyneco-Obstetric and Pediatric Hospital, GGO: Ground Glass Opacification; CT: Computerised Tomography, PCR: Polymerase Chain Reaction, CRP: C-Reactive Protein; RDT-Ag: Antigen Rapid Diagnostic Test, CPK: Creatine Phosphokinase; LDH: Lactate Dehydrogenase, PCT: Procalcitonin

Table 4. Treatment, obstetrical and materno-fetal outcome characteristics.

\begin{tabular}{ccc}
\hline Variables & Total & Percentage \\
\hline Maternal Outcome & $\mathrm{n}=18$ & $\%$ \\
Alive & 14 & 77.8 \\
Dead & 04 & 22.2 \\
Gestational Age (weeks) & $\mathrm{n}=13$ & $\%$ \\
$<34$ & 04 & 30.8 \\
{$[34-37]$} & 03 & 23 \\
Sex & $\mathrm{n}=13$ & $\%$ \\
Female & 07 & 53.8 \\
Male & 06 & 46.2 \\
\hline
\end{tabular}




\section{Continued}

\begin{tabular}{|c|c|c|}
\hline Birth Weight (g) & $\mathrm{n}=13$ & $\%$ \\
\hline$<2500$ & 04 & 30.8 \\
\hline $2500-3499$ & 06 & 46.2 \\
\hline [3500 - 3999] & 02 & 15.5 \\
\hline$\geq 4000$ & 01 & 07.7 \\
\hline APGAR $1^{\text {st }} \min$ & $\mathrm{n}=13$ & $\%$ \\
\hline$<7$ & 05 & 38.5 \\
\hline$\geq 7$ & 08 & 61.5 \\
\hline APGAR $5^{\text {th }} \min$ & $\mathrm{n}=13$ & $\%$ \\
\hline$<7$ & 03 & 23 \\
\hline$\geq 7$ & 10 & 77 \\
\hline Admission in NICU & $\mathrm{n}=13$ & $\%$ \\
\hline Yes & 08 & 61.5 \\
\hline No & 05 & 38.5 \\
\hline COVID-19 test & $\mathrm{n}=13$ & $\%$ \\
\hline Requested & 06 & 46.2 \\
\hline Done & 03 & 50 \\
\hline Results: Negative & 03 & 100 \\
\hline Treatment received & $\mathrm{n}=18$ & $\%$ \\
\hline Standard treatment & 18 & 100 \\
\hline Other treatment & 00 & 00 \\
\hline Mode of delivery & $\mathrm{n}=18$ & $\%$ \\
\hline Vaginal & 05 & 27.8 \\
\hline Cesarean section & 08 & 00 \\
\hline Instrumental & 00 & 44.4 \\
\hline Ongoing pregnancy & 05 & 27.8 \\
\hline
\end{tabular}

NICU: Neonatal Intensive Care Unit.

Breast feeding was practiced in $80 \%$ of the cases while respecting protective measures (Table 4).

\section{Discussion}

Our clinical data reveals that amongst all the 44 pregnant women admitted at the DGOPH during the study period, 13 of them were due to COVID-19, giving a general admission proportion of $29.5 \%$. These figures are much higher than the $0.3 \%$ reported in Senegal, a similar sub-Saharan country which recorded its first case at about the same time as Cameroon and the admission rate of $0.49 \%$ recorded in the UK [11] [12]. This could be explained by the fact that our hospital being a referral hospital for pregnant women, might have induced a selection bias, since over $60 \%$ were referred. The age range of our patients 30 - 39 years was similar to the median age of 34 recorded in the UK, and the 29 - 32 years old reported in a systematic review of 18 studies, mainly Chinese [13]. The Senegalese population had younger ages, with 20 - 25 years old the most represented [11]. 
Almost all available data converge to the fact that most pregnant women are diagnosed at 3rd trimester [11] [12] [13] [14]. Fever and cough have been shown to be the most common presenting symptom in larger cohort studies and our findings were consistent with this pattern [12] [13]. In Senegal, headache and fever were the leading symptoms while in Hubei Hospital, the primary epicenter of the novel coronavirus pandemic in China, the patients reported with fewer respiratory symptoms upon admission [11] [14]. However, most of these Chinese patients had typical chest CT scan images of COVID-19 pneumonia [14] [15].

Confirmation by PCR is the standard of care in most studies, though in three of our 18 patients we used RDT and chest CT-scan [11] [12] [13]. Our biological markers of severity were congruent with those used by several authors [13] [14]. Procalcitonin and D-dimers are not typically used in most studies. In Hubei, suspected patients with typical chest CT imaging but negative PCR tests were included due to overburdened health care system [14]. Similarly, as in Hubei hospital, all 09 of our patients with chest CT scan had typical ground glass opacities, with 6/9 having at least 50 percent lung involvement [14] [15]. Only 3 of our 18 patients had chronic medical conditions, a figure much lower than the 34 on 145 admissions reported in the British study, though the latter study had a larger population [12].

Our $62 \%$ caesarean section rate as mode of delivery is similar to that reported in the multicentric UK study which had 59\% [12]. However, in their systematic review of 86 deliveries of COVID-19 patients, they reported a 92\% caesarean section rate [13], while in Hubei, 14 of the 16 deliveries (80\%) were via caesarean [14]. Both of these figures are far higher than ours [13] [14]. Maternal respiratory distress was the primary indication for caesarean delivery.

Perhaps the most outstanding finding in our study is the $22.8 \%$ case fatality rate. Conversely, no maternal deaths were recorded in the systematic review of 108 patients from 4 case series and 14 case studies, as well as the review of 16 confirmed and 18 suspected cases in Hubei Provincial Maternity [13] [14]. Two third of our patients had less than normal oxygen saturation levels, half of them had at least 50\% lung involvement and up to $83 \%$ ICU admission rate. These reasons probably explain the high case fatality rates, as well as poor fetal outcomes.

It should be noted that all cases of COVID-19 related maternal deaths were recorded during the months of March and April 2020, when cases arrived too late to the hospital and DGOPH response team was still being fine-tuned. As the hospital with the highest level of referral in terms of maternal health, it is no surprise that the case selection was biased towards critical cases. Moreover, our study is a hospital study, in contrast to multicenter community-based studies which would have probably painted a less blink picture.

Though this was a novel primary research in our context, it had some limitations which included: 1) It didn't investigate factors influencing the relatively 
high ICU admission rates as well as the case fatality rates. 2) We couldn't therefore draw associations between COVID-19 and pregnancy. Future ongoing studies will elucidate the factors influencing these admission and fatality rates in pregnant COVID-19, pregnant non-COVID-19 and non-pregnant COVID-19 women managed at the DGOPH.

\section{Conclusion}

The clinical and paraclinical profile of COVID-19 pregnant women in Douala-Cameroon tends to be similar to what is observed around the world. However, the high ICU admission rate and high case fatality rates recorded differ from what is observed worldwide.

\section{Perspectives}

Poor patient outcomes recorded in this study warrants a more detailed look at the profile of the patients and pitfalls that might have occurred in patient care and timing of deliveries.

\section{Author Contributions}

All authors participated actively in this study and they read and approved its final version.

\section{Acknowledgements}

We are sincerely grateful to all the medical and technical staff of the Gynecology and Obstetrics Service, the emergency unit, the intensive care unit, the imaging and laboratory units, the internal medicine unit, the theatre and the outpatient department of gynecology and obstetrics and to the general administration of the DGOPH. Special thanks go to: Drs. Ze Mviana Marie Leonie Kelly, Makota Ndongo Grace, Noura Benmoussa, Eyanga Olivia, Bomba Ebede Michele, Gimma Nwanlih Gerdind, Ndjeumen Cynthia, Medjo Abomo Line, Pondy Victorine Marie, Ngo Dieu Liliane, Elame Emmanuel Frank, Tsala Jean Marie, Essaga Christele, Ntonga Davy, Chana Modestine and Mrs Elokam of the Pediatrics unit.

\section{Conflicts of Interest}

The authors declare no conflicts of interest regarding the publication of this paper.

\section{References}

[1] Matt, R. (2020) What Is Coronavirus and How Close Is It to Becoming a Pandemic? Wired UK.

[2] World Health Organization. Coronavirus Disease (COVID-2019) Situation Reports. https://www.who.int/emergencies/diseases/novel-coronavirus-2019

[3] Kouagheu, J. (2020) Cameroon Confirms First Case of Coronavirus. Reuters. 
[4] Cameroon Confirms 1st Death from COVID-19. http://www.aa.com.tr

[5] CRTVweb [@CRTV_web] (2020) 7 mesures supplémentaires contre la propagation du \#COVID19 au Cameroun Mesure 1: Port du masque obligatoire.

[6] MINSANTE-COVID-19 Press Release. http://COVID19.minsante.cm

[7] Asadi, L., Tabatabaei, R.S., Nejad, H.S. and Mohammadi, M. (2020) New Corona Virus (COVID-19) Management in Pregnancy and Childbirth. Archives of Clinical Infectious Diseases, 15, e102938. https://doi.org/10.5812/archcid.102938

[8] Qiao, J. (2020) What Are the Risks of COVID-19 Infection in Pregnant Women? The Lancet, 395, 760-762. https://doi.org/10.1016/S0140-6736(20)30365-2

[9] Liu, Y., Chen, H., Tang, K. and Guo, Y. (2020) Clinical Manifestations and Outcome of SARS-CoV-2 Infection during Pregnancy. Journal of Infection. https://doi.org/10.1016/j.jinf.2020.02.028

[10] Chen, H., Guo, J., Wang, C., Luo, F., Yu, X., Zhang, W., et al. (2020) Clinical Characteristics and Intrauterine Vertical Transmission Potential of COVID-19 Infection in Nine Pregnant Women: A Retrospective Review of Medical Records. The Lancet, 395, 809-815. https://doi.org/10.1016/S0140-6736(20)30360-3

[11] Diouf, A.A., Mbaye, K.D., Gueye, M., Thioub, D., Niang, N., Yonta Dekou, C., et al. (2020) Clinical Characteristics and Outcomes of COVID-19 Infection in Nine Pregnant Women: A Report from a Sub-Saharan African Country, Senegal. Pan African Medical Journal, 35, 58.

https://doi.org/10.11604/pamj.supp.2020.35.2.23736

[12] Knight, M., Bunch, K., Vousden, N., Morris, E., Simpson, N., Gale, C., et al. (2020) Characteristics and Outcomes of Pregnant Women Admitted to Hospital with Confirmed SARS-CoV-2 Infection in UK: National Population-Based Cohort Study. BMJ, 369, m2107. https://doi.org/10.1101/2020.05.08.20089268

[13] Zaigham, M. and Anderson, O. (2020) Maternal and Perinatal Outcomes with COVID-19: A Systematic Review of 108 Pregnancies. Acta Obstetricia et Gynecologica Scandinavica, 99, 823-829. https://doi.org/10.1111/aogs.13867

[14] Li, N., Han, L., Peng, M., et al. (2020) Maternal and Neonatal Outcomes of Pregnant Women with COVID-19 Pneumonia: A Case-Control Study. Clinical Infectious Diseases, ciaa352. https://doi.org/10.1101/2020.03.10.20033605

[15] Guan, W., Ni, Z., Yu, H., et al. (2020) Clinical Characteristics of Coronavirus Disease 2019 in China. The New England Journal of Medicine, 382, 1708-1720. https://doi.org/10.1056/NEJMoa2002032

$\begin{array}{ll}\text { Abbreviations } & \\ \text { COVID-19 } & \text { Corona Virus Disease of 2019 } \\ \text { DGOPH } & \text { Douala Gyneco-Obstetric and Pediatric Hospital } \\ \text { GGO } & \text { Ground Glass Opacification } \\ \text { ICU } & \text { Intensive Care Unit } \\ \text { NICU } & \text { Neonatal Intensive Care Unit } \\ \text { PCR } & \text { Polymerase Chain Reaction } \\ \text { PPE } & \text { Personal Protective Equipment } \\ \text { WHO } & \text { World Health Organization }\end{array}$




\section{Appendix}

REPUBLIQUE DU CAMEROUN

Paix-Travail-Patrie

MINISTERE DE LA SANTE PUBLIQUE

HOPITAL GYNECO-OBSTETRIQUE

ET PEDIATRIQUE DE DOUALA

(HGOPED)

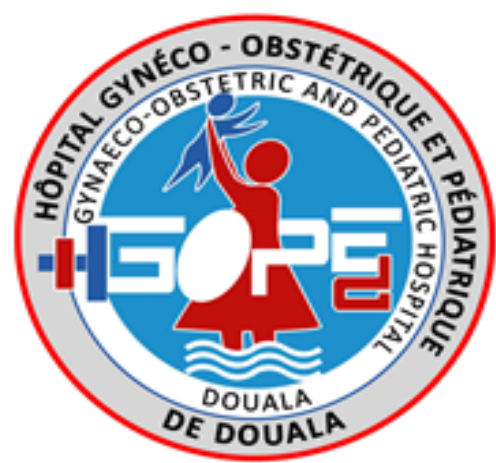

REPUBLIC OF CAMEROON

Peace-Work-Fatherland

MINISTRY OF PUBLIC HEALTH

DOUALA GYNAECO-OBSTETRIC

AND PEDIATRIC HOSPITAL

(DGOPH)

TASK FORCE FOR THE FIGHT AGAINST THE NOVEL CORONAVIRUS (SARS-Cov-2) PANDEMIC DATA SCREEN FOR COVID-19 SUSPECTED AND CONFIRMED CASES

\section{QUESTIONNAIRE COVID-19 IN PREGNANT WOMEN}

\section{Identification:}

a/Name ID:

b/Age (years):

c/ Parity:

e/Level of education: i/Primary

f/Marital status: $\quad$ i/Married

ii/Secondary

ii/Single

g/Recent travels: i/Douala

ii/Yaounde

h/Recent COVID contacts: i/None

ii/COVID suspect iii/COVID + confirmed

\section{Presenting Symptoms:}
a/Asymptomatic
b/Catarrh/sneezing
c/Cough
d/Fever
e/Headaches
f/Fatigue
g/Arthralgia/myalgia h/Dyspnoea
i/Diarrhoea
j/Dysphagia
k/Anosmia/Ageusia
1/Others

\section{Past History:}

$\begin{array}{llll}\text { a/Period of pregnancy: } & \text { i/Trimester } 1 & \text { ii/Trimester } 2 & \text { iii/Trimester } 3 \\ & \text { iv/Labour/Delivery } & \text { v/Postpartum } & \\ \text { b/Medications: } & \text { i/Iron } & \text { ii/Calcium } & \text { iii/Others } \\ & \text { iv/NSAIDs } & \text { v/None } & \text { vi/Traditional } \\ \text { c/IPT: } & \text { i/Normal for GA } & \text { ii/Subnormal for GA } & \text { iii/Not Yet eligible } \\ \text { d/Uterine surgery: } & \text { i/Yes } & \text { ii/No } & \\ \text { e/Chronic medical condition: } & \text { i/HBP } & \text { ii/Diabetes } & \text { iii/Obesity } \\ & \text { v/HIV } & \text { vi/Sickle cell anemia } & \text { vii/Cancer treatment } \\ & \text { viii/Asthma } & \text { ix/Kidney disease } & \text { x/Liver disease } \\ & \text { xi/Heart disease } & \text { xii/TB } & \text { xiii/Coagulopathy/DVT } \\ \text { i/A } & \text { ii/B } & \text { iii/AB }\end{array}$




\section{Physical Examination:}

\begin{tabular}{|c|c|c|c|c|}
\hline $\mathrm{a} / \mathrm{SaO}_{2}:$ & $\mathrm{i} /<70 \%$ & ii/70\% - 84\% & iii/85-98\% & $\mathrm{iv} />98 \%$ \\
\hline b/Respiratory rate (cpm): & $\mathrm{i} / 12-22$ & $\mathrm{ii} / 23-29$ & $\mathrm{iii} / \geq 30$ & \\
\hline c/HR (bpm): & $\mathrm{i} / 60-88$ & ii/89 - 119 & $\mathrm{iii} / \geq 120$ & \\
\hline
\end{tabular}

5. Working Diagnosis:

a/Non COVID b/suspected case COVID

c/Confirmed case COVID +

\section{Paraclinical Biological Examination:}

\begin{tabular}{|c|c|c|c|c|}
\hline a/Throat swab PCR: & i/COVID+ & ii/COVID- & iii/Ambiguity & \\
\hline b/Serologic testing: & i/Positive & ii/Negative & iii/Ambiguity & \\
\hline c/FBC: & i/All Normal & ii/Anemia & iii/Lymphopenia & iv/Thrombopenia \\
\hline d/Clotting profile: & i/Abnormal & ii/Normal & iii/Borderline & \\
\hline e/CRP: & i/Positive & ii/Negative & & \\
\hline f/LDH: & i/Positive & ii/Negative & & \\
\hline g/Proteinuria: & i/Positive & ii/Negative & & \\
\hline h/Liver function tests: & i/Abnormal & ii/Normal & iii/Borderline & \\
\hline i/CPK: & i/Positive & ii/Negative & & \\
\hline g/D-Dimers: & i/Positive & ii/Negative & & \\
\hline
\end{tabular}

\section{Paraclinical Morphological Examinations:}

$\begin{array}{llll}\text { a/Indication: } & \text { i/Screening } & \text { ii/Severe symptoms } & \text { iii/Follow up treatment } \\ \text { b/Chest CT Scan results: } & \text { i/Normal } & \text { ii/GGO } & \text { iii/Other lesions } \\ \text { c/If GGO, severity score: } & \text { i/Mild 25\% } & \text { ii/Moderate 50\% } & \text { iii/Severe 75\% }\end{array}$

8. Management during Pregnancy:

a/Use of barrier measures:
b/Respect of social distancing:
c/Hydroxychloroquine use:
d/Azithromycin use:
e/Zinc and other trace elements:
f/Corticosteroids use:
g/Heparin use:
h/Other antibiotics used:
i/Oxygen assistance /No intubation:
j/Intubation:
k/Place of management:
l/Number of ANC:

$\begin{array}{ll}\text { i/Yes } & \text { ii/No } \\ \text { i/Yes } & \text { ii/No } \\ \text { i/Yes } & \text { ii/No } \\ \text { i/Yes } & \text { ii/No } \\ \text { i/Yes } & \text { ii/No } \\ \text { i/Yes } & \text { ii/No } \\ \text { i/Yes } & \text { ii/No } \\ \text { i/Yes } & \text { ii/No } \\ \text { i/Yes } & \text { ii/No } \\ \text { i/Yes } & \text { ii/No } \\ \text { i/Home } & \text { ii/Emergency admission } \\ \text { i/None } & \text { ii/1 } 2\end{array}$

iii/ICU admission ii/1 - 2

iii/3 - 4

iv/ $>4$

9. Management during Labor /Delivery:
a/GA at delivery:
b/Epidural anesthesia:
c/Barrier measures used:
d/Mode of delivery:

$\begin{array}{ll}\text { i/Preterm } & \text { ii/Term } \\ \text { i/Yes } & \text { ii/No } \\ \text { i/Yes } & \text { ii/No }\end{array}$

i/Vaginal ii/Instrumental
iii/C/S 


\begin{tabular}{|c|c|c|c|c|}
\hline e/Birth asphyxia & $\mathrm{i} / \mathrm{Yes}$ & ii/No & & \\
\hline f/Neonate transferred to NICU: & $\mathrm{i} / \mathrm{Yes}$ & ii/No & & \\
\hline g/Delivery assisted by: & $\mathrm{i} / \mathrm{O} \& \mathrm{G}$ & ii/Resident O\&G & iii/Midwife & \\
\hline \multicolumn{2}{|c|}{ h/Full protective gear used by delivery personnel: } & $\mathrm{i} /$ Yes & ii/Incomplete & iii/No \\
\hline \multirow{2}{*}{\multicolumn{2}{|c|}{$\begin{array}{l}\text { i/Place of delivery: i/Common delivery room } \\
\text { j/Hydroxychloroquine chemoprophylaxis: }\end{array}$}} & ii/COVID delivery room & iii/Elsewhere & \\
\hline & & $\mathrm{i} /$ Yes & $\mathrm{ii} / \mathrm{No}$ & \\
\hline \multicolumn{2}{|c|}{$\mathrm{k} / \mathrm{Number}$ of doses of corticosteroid received if $\mathrm{pr}$} & & & \\
\hline
\end{tabular}

\section{Management during Postpartum:}

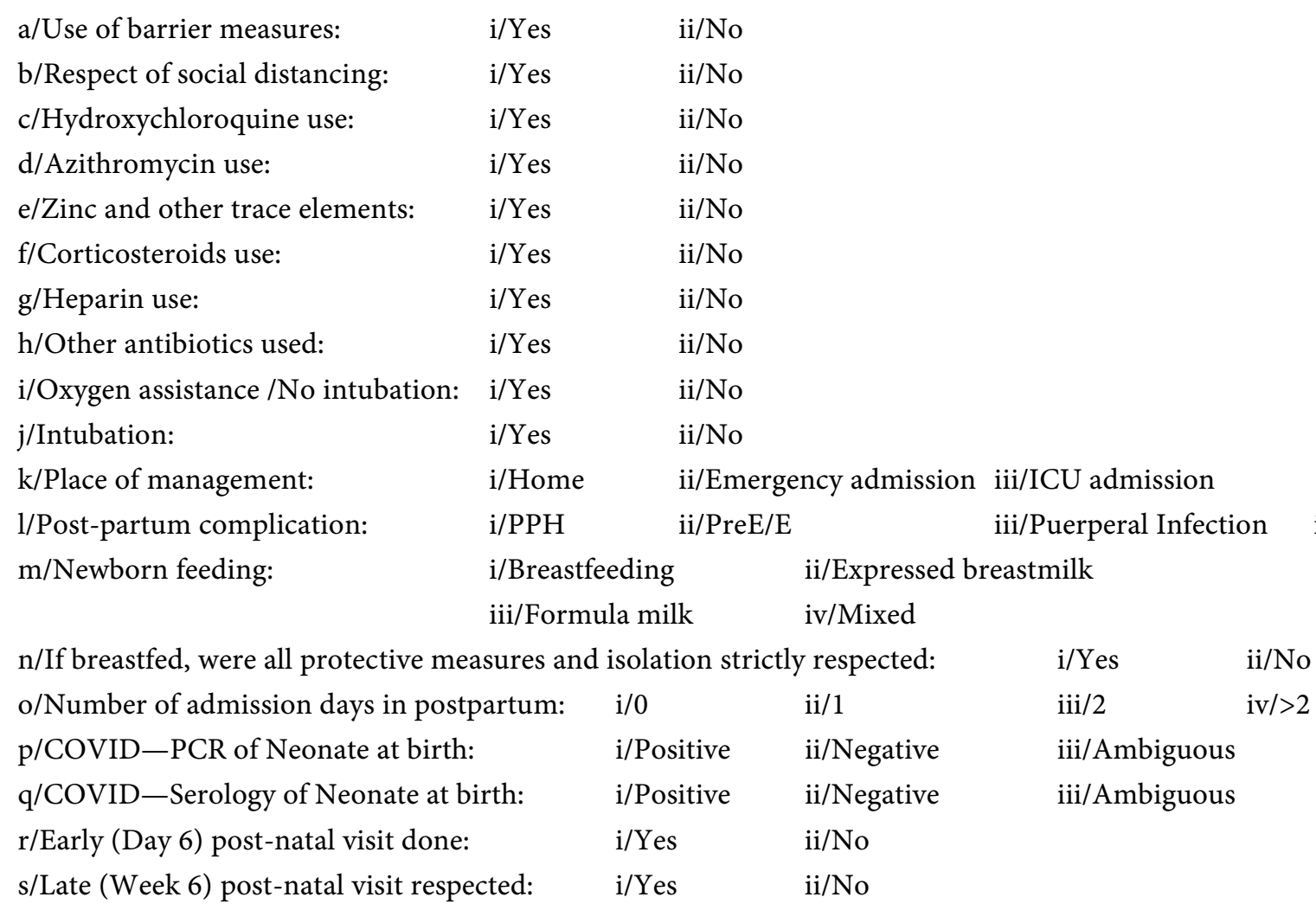

\section{Follow up and outcomes:}
a/Survival outcomes:
i/Cured and discharged
ii/Prolonged admission
ii/Positive
ii/Positive
iii/Death
b/Throat swab PCR results at Day 14: i/Negative
iii/Ambiguous
iii/Ambiguous 